\title{
Infantile neuronal ceroid lipofuscinosis
}

INSERM

\section{Source}

INSERM. (1999). Orphanet: an online rare disease and orphan drug data base. Infantile neuronal ceroid lipofuscinosis. ORPHA:79263

Infantile neuronal ceroid lipofuscinosis (INCL) is a form of neuronal ceroid lipofuscinosis ( $N C L$; see this term) characterized by onset during the second half of the first year of life and rapid mental and motor deterioration leading to loss of all psychomotor abilities. 